\title{
Functional Properties of Two Bombesin-Like Peptide Receptors Revealed by the Analysis of Mice Lacking Neuromedin B Receptor
}

\author{
Hiroko Ohki-Hamazaki, ${ }^{1,2}$ Yasushi Sakai, ${ }^{3}$ Katsuo Kamata, ${ }^{4}$ Hiroo Ogura,, ${ }^{5}$ Shigeru Okuyama,, ${ }^{6}$ Kei Watase, ${ }^{2}$ \\ Kazuyuki Yamada, ${ }^{2}$ and Keiji Wada ${ }^{2}$ \\ ${ }^{1}$ Department of Neurochemistry, Tokyo Institute of Psychiatry, Setagaya-ku, Tokyo 156-8585, Japan, 2Department of \\ Degenerative Neurological Diseases, National Institute of Neuroscience, National Center of Neurology and Psychiatry, \\ Kodaira, Tokyo 187-8502, Japan, ${ }^{3}$ Laboratory of Physiology, Department of Occupational Therapy, College of Medical \\ Sciences, Showa University, Midori-ku, Yokohama, Kanagawa 226-8555, Japan, ${ }^{4}$ Department of Physiology and \\ Morphology, Institute of Medicinal Chemistry, Hoshi University, Shinagawa-ku, Tokyo 142-0063, Japan, 5 Tsukuba \\ Research Laboratories, Eisai Company, Tsukuba, Ibaraki 300-2635, Japan, and ${ }^{6} 1$ st Laboratory, Medicinal Research \\ Laboratories, Taisho Pharmaceutical Company, Ohmiya, Saitama 330-8530, Japan
}

The neuromedin B-preferring receptor (NMB-R) is one of the members of the bombesin (BN)-like peptide receptor subfamily in mammals. Previously, we have generated and characterized mice with targeted disruption of the two other BN-like peptide receptors, bombesin receptor subtype-3 (BRS-3) and gastrinreleasing peptide-preferring receptor (GRP-R). Here we describe the generation and analysis of NMB-R-deficient mice to investigate how NMB-R differs from BRS-3 and GRP-R. Compensation for NMB-R deficiency by overexpression of GRP-R and/or BRS-3 was not detected. Although the hypothermic effect of NMB was reduced by $50 \%$ in NMB-R-deficient mice, the effect of GRP infusion was comparable to the wild-type mice. In contrast, fundic smooth muscle contraction on stimu- lation with NMB or GRP was normal in NMB-R-deficient mice. Administration of GRP but not NMB suppressed glucose intake in both normal and NMB-R-deficient mice. These results suggest that the NMB-R has an essential role in thermoregulation, but not for smooth muscle contraction of the fundus or for the suppression of feeding behavior. In addition, the behavioral phenotypes of GRP-R-deficient mice were not observed in NMB-R-deficient mice. These data show that the functions of NMB-R and GRP-R are distinct, with only partial overlap.

Key words: neuromedin B receptor; gastrin-releasing peptide receptor; smooth muscle contraction; thermoregulation; feeding suppression; social behavior; knock-out mice
Neuromedin B (NMB) is widely distributed in brain and the gastrointestinal tract of mammals and is a member of the bombesin (BN)-like peptide family (Minamino et al., 1983; Krane et al., 1988; Wada et al., 1990). BN was purified initially from amphibian skin (Anastasi et al., 1971), and its varied biological functions have been characterized (for review, see Lebacq-Verheyden et al., 1990). These include modulation of nervous system activity and alteration in gastrointestinal tract, cell growth, and development. In addition to NMB, the gastrin-releasing peptide (GRP) is a mammalian counterpart of the BN (McDonald et al., 1979; Spindel et al., 1984; Lebacq-Verheyden, 1988; Wada et al., 1990). Despite extensive pharmacological studies on the activity of BN when administered to mammals, little is known about the physiological function of NMB or GRP.

By using molecular cloning techniques, three receptors, NMBpreferring receptor (NMB-R), GRP-preferring receptor (GRP$\mathrm{R}$ ), and bombesin receptor subtype-3 (BRS-3), have been cloned

\footnotetext{
Received Sept. 10, 1998; revised Nov. 17, 1998; accepted Nov. 20, 1998.

This work was supported in part by research grants from the Ministry of Education, Science, Sports and Culture of Japan, the Ministry of Health and Welfare of Japan, the Science and Technology Agency of Japan, and the Japan Foundation for Human Health. We thank Dr. J.-I. Miyazaki for ES cells, Dr. E. Wada for the mouse GRP-R cDNA clone and useful discussions, Dr. Y. Ogihara for useful discussions, and Drs. R. Gruener and R. Petralia for critical reading of this manuscript.

Correspondence should be addressed to Dr. Hiroko Ohki-Hamazaki, at his present address: Department of Molecular Neuroscience, Medical Research Institute, Tokyo Medical and Dental University, 1-5-45 Yushima, Bunkyo-ku, Tokyo 113-8519, Japan.

Copyright (C) 1999 Society for Neuroscience $\quad 0270-6474 / 99 / 190948-07 \$ 05.00 / 0$
}

(Spindel et al., 1990; Battey et al., 1991; Corjay et al., 1991; Wada et al., 1991; Gorbulev et al., 1992; Fathi et al., 1993; OhkiHamazaki et al., 1997a). An endogenous ligand for BRS-3 has not yet been identified. These receptors are G-protein-coupled and have different relative affinities for NMB, GRP, and BN (Wada et al., 1991; Gorbulev et al., 1992; Fathi et al., 1993). In brain, the expression of the NMB-R, but not the GRP-R or BRS-3, has been observed in olfactory regions and in the thalamus. In many other brain areas, including isocortex, hippocampus, amygdala, hypothalamus, and brain stem, NMB-R is colocalized with GRP-R (Wada et al., 1992). Moreover, BRS-3 also is expressed in the amygdala, hypothalamus, and brain stem (Ohki-Hamazaki et al., 1997a; Yamada K, Wada E, Imaki J, Ohki-Hamazaki H, Wada K, unpublished observations).

Such wide distribution of expression of these receptors in brain is consistent with the wide spectrum of biological activity of $\mathrm{BN}$. In many brain regions, more than two receptor subtypes are expressed, and these BN-like peptide receptors can bind both NMB and GRP with different affinities. Therefore, it is difficult to evaluate the contribution of each receptor subtype in affecting distinct physiological response to $\mathrm{BN}, \mathrm{GRP}$, or NMB. One way to resolve this problem is to use specific antagonists to these receptors. A complementary approach is to use molecular genetic methods to eliminate receptor expression. This is particularly important when attempts are made to obtain information about the physiological functions of the receptors at the whole-animal level (Ohki-Hamazaki et al., 1997b; Wada et al., 1997). 
Here we report the generation and characterization of NMBR-deficient mice. We focused on elucidating the functional properties of two BN-like peptides and their receptors: NMB, GRP, NMB-R, and GRP-R. For this purpose, we evaluated the effect of NMB or GRP application on NMB-R deficient mice and compared the behavior of the NMB-R-deficient mice with that of the GRP-R-deficient mice (Wada et al., 1997). We discuss the contributions of these peptides and receptors in thermoregulation, smooth muscle contraction, feeding suppression, and behavior.

\section{MATERIALS AND METHODS}

Targeted disruption of the NMB-R gene and generation of mutant mice. For constructing the targeting vector, a $9.5 \mathrm{~kb}$ SacII-SmaI fragment containing the $3^{\prime}$ region of exon 1 , the entire exon 2 , and the $5^{\prime}$ region of exon 3 of the NMB-R gene was cloned from a 129SV mouse genomic library. A $1.3 \mathrm{~kb}$ PstI-PstI fragment containing exon 2 was inactivated by substitution with Neo-cassette from $\mathrm{pKJ} 2$ as described previously (OhkiHamazaki et al., 1997b). The diphtheria toxin (DT) gene for negative selection (Yagi et al., 1993) was ligated to the 3 ' position of the targeting vector (see Fig. $1 A$ ). The E14 embryonic stem (ES) cell line was transfected with a linearized vector by electroporation, resulting in one homologous recombinant out of 289 G418 resistant clones screened. DNA was digested with $B g l \mathrm{II}$ and $S p e I$, and restriction fragments were detected by Southern analysis using the indicated 5' probe (a NotI-SacII fragment). To confirm the correct homologous recombination event, EcoRI- and AccI-digested fragments were detected with a $3^{\prime}$ probe (a EcoRV-PstI fragment), and EcoRI-digested fragments were also detected with a Neo probe (see Fig. $1 B$ ). ES cells of this clone were injected into the blastocysts of B6, and chimeric embryos were implanted into the uterus of pseudopregnant Jcl:ICR mice. Chimeric male mice then were mated with female B6 mice, and germline transmission of the ES cells was confirmed. For backcrossing, females carrying the heterozygous allele of NMB-R were mated with a C57BL/6J male. Genotyping of mice also was performed by PCR with indicated primers (see Fig. $1 A, a, b$, and $c$ ). Primer sequences are as follows: wild-type primer a, TCC TAG GTA CAG AGC TAT CGT GAA, and primer b, CCA CCA GCT GCC TTT GGC TTT G; mutant primer c, TAC GGT ATC GCC GCT CCC GAT T.

Receptor autoradiography. Mice were deeply anesthetized and decapitated, and the brains were immediately removed and frozen. Coronal sections of $20 \mu \mathrm{m}$ cut on a cryostat were taken at the level of the olfactory and thalamic areas containing some regions expressing exclusively NMB-R of the three BN-like peptide receptors (Wada et al., 1992). Tissue sections were incubated for $6 \mathrm{hr}$ at room temperature with $40 \mathrm{pM}$ ${ }^{125} \mathrm{I}$-[Tyr ${ }^{15}$ ]GRP (Amersham, Arlington Heights, IL), with or without the addition of $1 \mu \mathrm{M}$ BN (Sigma, St. Louis, MO). Autoradiography was performed according to Kris et al. (1987).

Semiquantitative RT-PCR. Poly $\left(\mathrm{A}^{+}\right)$RNA was prepared from wildtype and NMB-R-deficient male mouse brains using the FastTrack mRNA isolation kit (Invitrogen, San Diego, CA). Two hundred nanograms of mRNA from whole brains were reverse-transcribed in a $20 \mu \mathrm{l}$ reaction mixture as described previously (Ohki-Hamazaki et al., 1997a). For semiquantitative PCR for brain cDNA, $1 \mu \mathrm{l}$ of cDNA solution was used for $\beta$-actin gene amplification. Aliquots were removed from the reaction mixture every two cycles starting at cycle 18 through cycle 30 . Because the amount of amplified products was almost the same for cDNA solutions from wild-type and NMB-R-deficient mice, the same volume of cDNA solutions from each genotype was subjected to PCR for BN-R gene amplification. We used $3 \mu$ l of cDNA solution for NMB-R and GRP-R gene amplification, respectively, and $5 \mu$ l for BRS-3 gene amplification, because the expression level of BRS-3 in whole brain is lower than two other receptors (Ohki-Hamazaki et al., 1997a). Aliquots of each PCR products were removed every two cycles from 22-32 cycles. The primers used were already described (Ohki-Hamazaki et al., 1997a) except for GRP-R (5'-ATG CCA GCA AGT ACC TGG CTG AC-3' and 5'-GGA GGT GTC CAC TTC AGA GTA GTG-3'). We designed these primers at the corresponding sites of three genes. Forward primers were located at the $3^{\prime}$ region of the first exon of each gene, and the reverse primers were at the $5^{\prime}$ region of the third exon. Amplification efficiencies by each primer pair were examined using plasmids containing each cDNA as a template. These plasmids for NMB-R and BRS-3 genes were already described (Ohki-Hamazaki et al., 1997a), and for the GRP-R gene, a $1.5 \mathrm{~kb}$ EcoRI fragment of mouse cDNA (Battey et al., 1991) (kindly provided by Dr. E. Wada, Department of Degenerative
Neurological Diseases, National Institute of Neuroscience, National Center of Neurology and Psychiatry) was subcloned into pBSKIIsk(-) and used. The concentration of each template was adjusted by amplifying the template using M13 forward (5'-GTT TTC CCA GTC ACG AC-3') and reverse $\left(5^{\prime}\right.$-CAG GAA ACA GCT ATG AC-3') primers.

Total RNA was isolated from fundus tissue of wild-type and NMBR-deficient mice using TRIZOL Reagent (Life Technologies, Gaithersburg, MD). Five micrograms of fundus total RNA from wild-type mice were reverse-transcribed in a $20 \mu \mathrm{l}$ reaction mixture, and $5 \mu \mathrm{l}$ of cDNA solution was used for the PCR comparing NMB-R and GRP-R expression levels. Otherwise, cDNA solution derived from $1 \mu$ l of total RNA from wild-type and NMB-R-deficient mice was used.

Rectal temperature. Male transgenic mice of F4 generation (backcrossed four times to C57BL/6) were used. Rectal temperatures of wild-type $(n=11)$ and NMB-R-deficient $(n=11)$ mice at $4-5$ months were monitored at ambient temperature $\left(26^{\circ} \mathrm{C}\right)$ using a thermister thermometer (Nihon Koden, Tokyo, Japan). Then, individually caged mice were kept at a low temperature $\left(4^{\circ} \mathrm{C}\right)$, and the rectal temperatures were recorded at the indicated times. For intracerebroventricular infusion of peptides, a 30 gauge needle was attached to a PE10 tube (Becton Dickinson, Mountain View, CA) and a $1 \mathrm{ml}$ syringe. The needle was inserted into the lateral ventricle. The location of the injection site was confirmed in cryostat sections after dye injection. Five microliters of solution containing $100 \mathrm{pmol}$ of either NMB (NMB porcine; Peninsula Laboratory) or GRP (GRP 14-27, porcine, human; Peninsula Laboratory) were administered. We used nine males and eight females of each genotype for NMB infusion, and 10 wild-type males and 13 NMB-Rdeficient males or 11 wild-type females and 10 NMB-R-deficient females for GRP infusion. We infused the same volume of saline into the contralateral ventricle as a control. Two infusions were separated by at least 1 week for the same mouse. Rectal temperatures were monitored using a thermister (BAT-12 Physitemp) equipped with a rectal probe (RET-3 Physitemp). Data were analyzed using two-tailed unpaired Student's $t$ test.

Smooth muscle contraction. The stomach was quickly removed from 2-month-old mice of F5 generation. We used eight wild-type and eight NMB-R-deficient mice for NMB application, and six mice of each genotype for GRP application. Surrounding fat and connective tissue were removed under a dissecting microscope. The tissues were bathed in Krebs'-Henseleit-bicarbonate (K-H) solution containing (in $\mathrm{mM}$ ): $\mathrm{NaCl}$ 115.0, $\mathrm{KCl}$ 4.7, $\mathrm{CaCl}_{2} 2.5, \mathrm{MgSO}_{4} 1.2, \mathrm{NaHCO}_{3} 25.0, \mathrm{KH}_{2} \mathrm{PO}_{4} 1.2$, and dextrose 10.0) at room temperature. The fundus was dissected and opened along the lesser curvature, and the contents were rinsed off with $\mathrm{K}-\mathrm{H}$ solution. Then the fundus was cut into two pieces along the longitudinal axis. One piece from each fundus was prepared for contractile study; the other was used for RNA preparation. For contractile studies, both ends of the piece were tied with fine thread, and then one end was attached to the muscle holder (lower end) and the other end (upper end) was connected to a force-displacement transducer (RECTIHORIZ-8k, Sanei). For isometric tension recording, each muscle strip was suspended in a bath containing $10 \mathrm{ml}$ of $\mathrm{K}-\mathrm{H}$ solution. The bath solution was maintained at $37 \pm 0.50^{\circ} \mathrm{C}$ and continuously bubbled with a gas mixture of $95 \% \mathrm{O}_{2}$ and $5 \% \mathrm{CO}_{2}$. Before the recordings were started, the muscle strips were stretched with $1.0 \mathrm{gm}$ tension and allowed to equilibrate for $60 \mathrm{~min}$ in $\mathrm{K}-\mathrm{H}$ solution, which was replaced every $15 \mathrm{~min}$. Then, a high- $\mathrm{K}^{+}(60 \mathrm{~mm} \mathrm{KCl})$ solution was applied to induce $\mathrm{K}^{+}$ contracture, and the solution was replaced by the standard K-H solution to reduce the tension to the basal level. The concentration-response curves for the agonists were determined by cumulative increases of concentration. Data were analyzed using a two-tailed paired Student's $t$ test.

Feeding suppression. Feeding suppression by the BN-like peptides was evaluated by measuring glucose intake of mice after peptide administration. Adult female NMB-R-deficient $(n=6)$ and wild-type $(n=9)$ mice at 4-7 months of age (weighing 21-28 gm) of F5 and F6 generation were subjected to this experiment. They were housed individually under $12 \mathrm{hr}$ light/dark cycle (light cycle begins at 8:00 A.M.), and food and water were available ad libitum except during the experimental sessions. All experiments were performed between 13:30 and 16:30 P.M. We followed the experimental procedures described by Hampton et al. (1998) with minor modifications. To familiarize mice with the experimental procedure, mice were administered an intraperitoneal injection of $0.9 \%$ saline $(1 \mathrm{ml} / 100 \mathrm{gm})$ and given immediate access to a glucose solution $(0.5$ $\mathrm{kcal} / \mathrm{ml}$ ) for $60 \mathrm{~min}$. These sessions were repeated five times. Mice were divided into two groups (each group involved wild-type and NMB-R- 


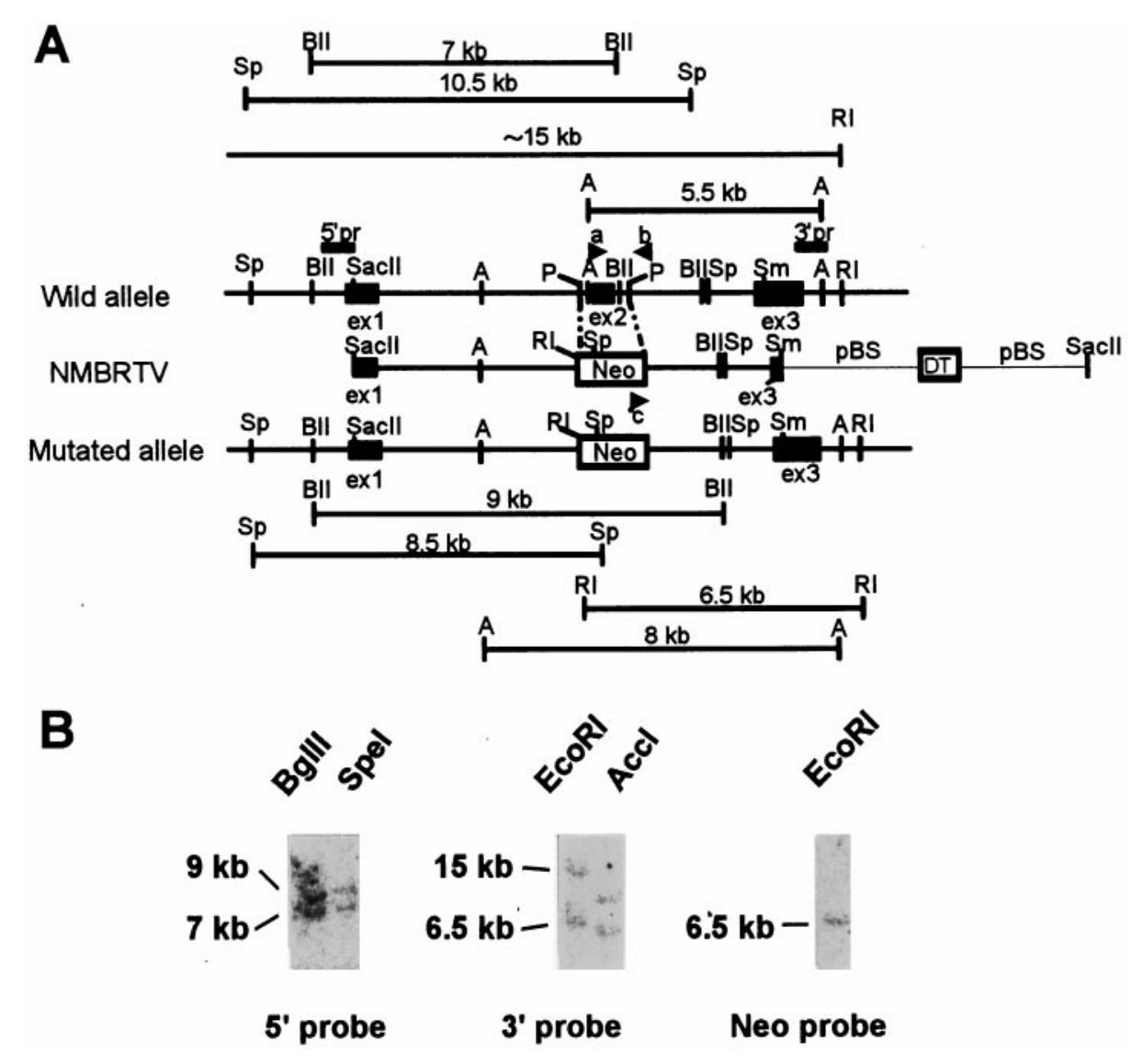

Figure 1. Targeted disruption of the NMB-R gene. $A$, Structure of the wild-type allele, genetargeting vector (NMBRTV), and mutated allele. Predicted lengths of restriction fragments for diagnosis are shown. $a, b$, and $c$ indicate the position of PCR primers used in genotyping. 5' $p r, 5^{\prime}$ probe; 3'pr, 3' probe; BII, BglII; $S p$, SpeI; RI, EcoRI; A, AccI; P, PstI; Sm, SmaI; $p B S$, pBluescript. $B$, Southern blot analysis of DNA prepared from a homologous recombinant ES clone. deficient mice), and each group was treated with NMB solution (32 $\mathrm{nmol} / \mathrm{kg}$, i.p., in a volume of $1 \mathrm{ml} / 100$ gm body weight) or saline. In the next session, which was separated by at least $24 \mathrm{hr}$ from the previous one, the alternative solution was given. In the next experiment, instead of NMB solution and saline, GRP solution $(32 \mathrm{nmol} / \mathrm{kg} ; 1 \mathrm{ml} / 100 \mathrm{gm}$ body weight) and saline were used. Each mouse was challenged twice with each peptide. Glucose intake was recorded at 30 and $60 \mathrm{~min}$ and was averaged across days for each mouse ( $4 \mathrm{~d}$ for saline and $2 \mathrm{~d}$ for NMB and GRP solutions). Data were analyzed using a two-tailed paired Student's $t$ test.

Behavioral measurements. Twenty-four hour activity was measured in individually caged male mice of F1 generation (seven wild-type and seven mutant mice at 4-7 months of age) in their home cage $(190 \times$ $260 \times 125 \mathrm{~mm}$ ) under $12 \mathrm{hr}$ light/dark cycle. NS-AS01 sensor (Neuroscience, Tokyo, Japan), which detects a movement of ultra-red radiating subjects, was used. For short-time activity, male mice of F5 generation (14 mice for each genotype at 3 months of age) were housed in a transparent cage $(300 \times 200 \times 130 \mathrm{~mm})$, and their activity was monitored using SCANET SV-10 (Toyo Sangyo, Toyama, Japan). Social interaction tests were performed using male mice of F4 generation (11 wild-type and 13 mutant mice) at 2-4 months of age. Methods have already been described (Wada et al., 1997), and statistical analyses were performed using two-tailed unpaired Student's $t$ test.

\section{RESULTS}

\section{Generation of NMB-R-deficient mice}

A genomic fragment containing all three exons of the NMB-R gene was used for the construction of the targeting vector and probes. A fragment containing exon 2 was deleted and substituted by Neo-cassette and ligated to the DT gene for negative selection (Yagi et al., 1993) (Fig. 1). E14 ES cells derived from a 129 strain mouse (Hooper et al., 1987) were transfected with the linearized vectors by electroporation. We identified one correctly targeted clone and generated chimeras by injecting this clone into blasto- cysts of $\mathrm{C} 57 \mathrm{BL} / 6 \mathrm{~J}$ mice. The chimeras were then mated with a C57BL/6J female, and we established a mutant mouse line.

Coronal sections of wild-type and mutant mice brain were prepared and subjected to ${ }^{125}$ I-GRP binding assay. With the concentration of ${ }^{125} \mathrm{I}$-GRP used in this assay, we can detect the binding of ${ }^{125}$ I-GRP to both GRP-R and NMB-R. In brain sections of NMB-R-deficient mice, ${ }^{125} \mathrm{I}$-GRP failed to bind to the anterior olfactory nucleus where only the NMB-R is present among the BN-like peptide receptors. The specificity of this reaction was confirmed by adding cold $\mathrm{BN}$. This means that the function of NMB-R was abolished in the mutant mice (Fig. 2A).

\section{Regulation of body temperature}

Because central administration of $\mathrm{BN}$ produces hypothermia (Pittman et al., 1980; Wunder et al., 1980; Lin and Lin, 1986) and the NMB-R is expressed in preoptic hypothalamic regions (Wada et al., 1992), which are known to be brain regions involved in body temperature regulation, we evaluated thermoregulation in these mutant mice. At $26^{\circ} \mathrm{C}$, rectal temperatures of mutant mice averaged $37.2 \pm 0.2^{\circ} \mathrm{C}$ and did not differ from those of the wild-type mice $\left(36.8 \pm 0.1^{\circ} \mathrm{C}\right)$. Even after exposure to $4^{\circ} \mathrm{C}$ for $2 \mathrm{hr}$, they did not show any abnormality in the regulation of body temperature (wild type, $33.7 \pm 0.6^{\circ} \mathrm{C}$; mutant, $33.7 \pm 0.6^{\circ} \mathrm{C}$ ) (Fig. $3 A$ ). We then determined the effect of NMB and GRP administration on the body temperature in these mice (Fig. $3 B$ ). NMB, GRP, or saline was infused in the lateral ventricle, and the change in rectal temperature was monitored for $2 \mathrm{hr}$. NMB lowered the rectal temperature by $2.4^{\circ} \mathrm{C}$ in wild-type males and $1.9^{\circ} \mathrm{C}$ in wild-type females after 15 min of infusion. However, in mutant mice, this change was $1.4^{\circ} \mathrm{C}$ in males and $0.8^{\circ} \mathrm{C}$ in females $(\sim 58 \%$ in males 
A

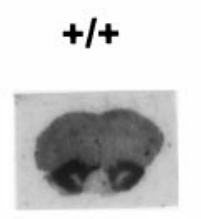

B

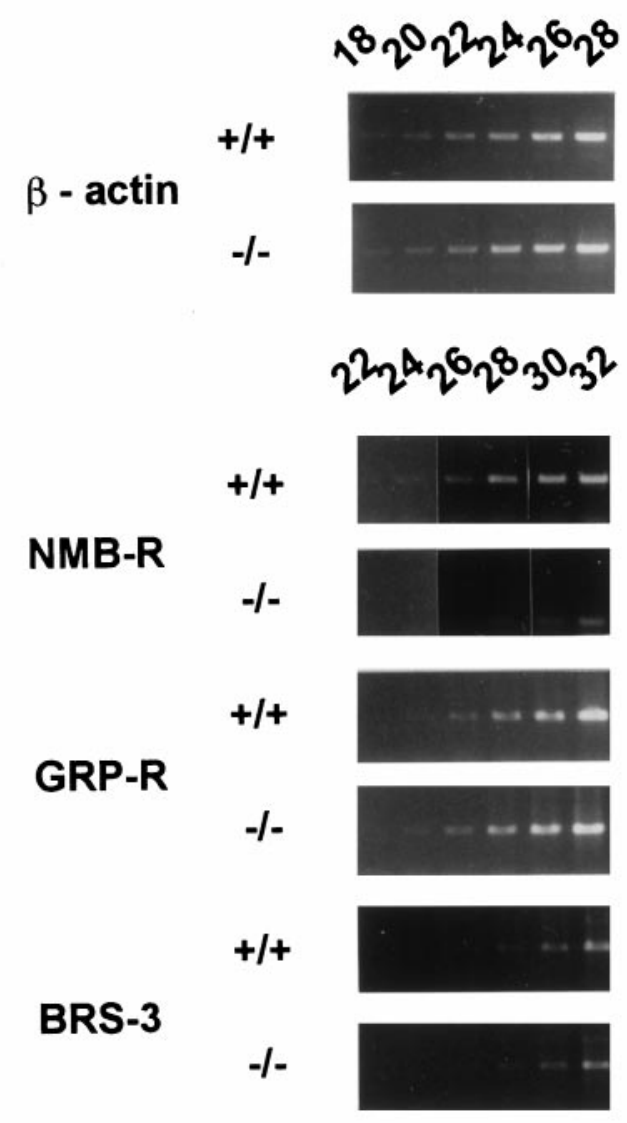

Figure 2. Expression of BN-like peptide receptors in NMB-R-deficient $(-/-)$ and control $(+/+)$ mouse brain. $A,{ }^{125}$ I-GRP binding to the brain section. Binding of ${ }^{125} \mathrm{I}$-GRP to the anterior olfactory nucleus, where NMB-R is expressed abundantly, is evident in the control mouse brain section, but ${ }^{125}$ I-GRP fails to bind to the same nucleus in the NMB-Rdeficient mouse. $B$, Expression levels of $\mathrm{BN}$-like peptide receptors in NMB-R-deficient mice compared with the wild-type-mice revealed by semiquantitative RT-PCR. Numbers at the top of the panels indicate the cycle numbers of PCR. PCR products for $\beta$-actin gene show that the quantity of cDNA template for both genotypes was equivalent. NMB-Rdeficient mice express only truncated forms of NMB-R gene and lack normal NMB-R-expression, and the expression levels of GRP-R and BRS-3 are not changed compared with the control mice.

and $41 \%$ in females of the values of the changes seen in wild-type mice). The effect of GRP injection on hypothermia was more prominent, because it lowered by $2.8^{\circ} \mathrm{C}$ in wild-type males and $3.6^{\circ} \mathrm{C}$ in wild-type females after $15 \mathrm{~min}$. The NMB-R-deficient mice exhibited similar hypothermic response to the GRP compared with the wild-type mice (male, $-2.7^{\circ} \mathrm{C}$; female, $-3.1^{\circ} \mathrm{C}$; not significantly different from the values seen in wild-type mice). Saline infusion did not lower the body temperature more than $1.2^{\circ} \mathrm{C}$ during the $120 \mathrm{~min}$ test period. These results showed that in the mice lacking NMB-R, adaptation to the ambient temperature was not affected, but the thermoregulatory response to NMB was diminished by $50 \%$, whereas the response to GRP was similar to wild-type controls.
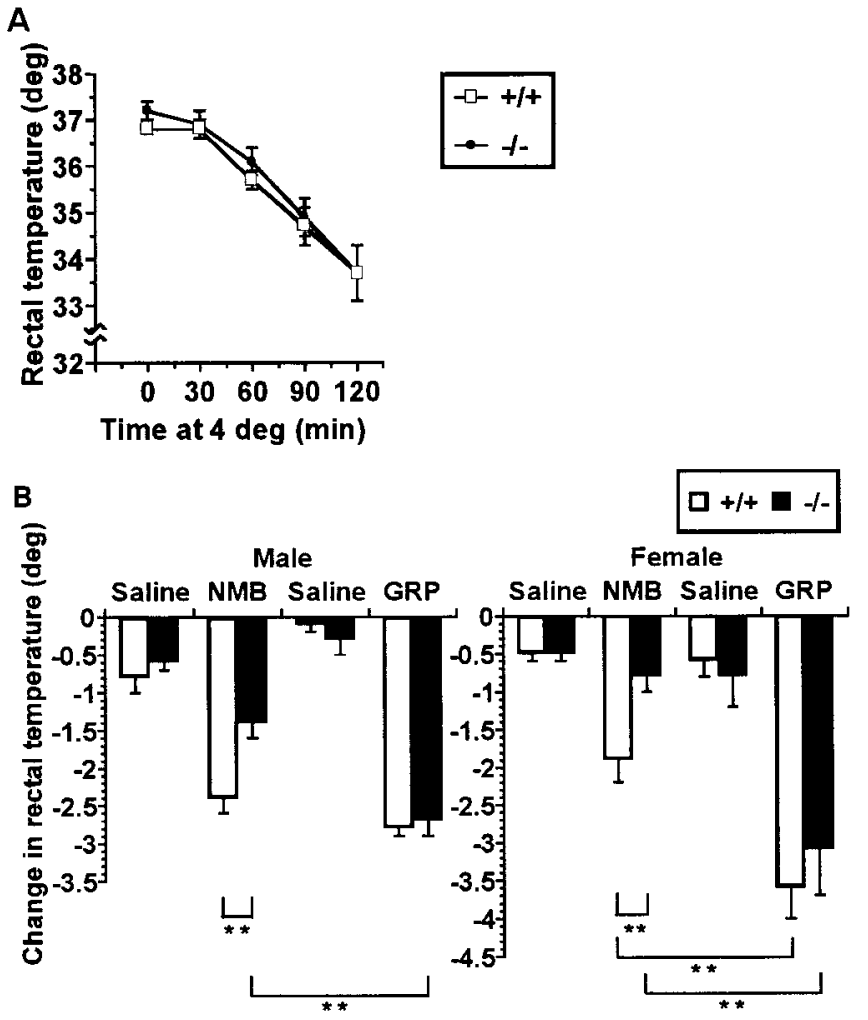

Figure 3. Regulation of body temperature in NMB-R-deficient mice. $A$, Thermoregulatory response at $4^{\circ} \mathrm{C}$. NMB-R-deficient mice did not show any deficiency in thermoregulation during cold exposure. $B$, Effect of ventricular infusion of NMB or GRP in thermoregulation. In both male and female mutant mice, the hypothermic response to NMB was reduced, although the response to GRP was unchanged compared with the wildtype mice. Values are mean \pm SEM. ${ }^{* *} p<0.01$.

\section{Expression level of BN-like peptide receptors in the brains of NMB-R-deficient mice}

We determined the expression levels of three BN-like peptide receptors in the brains of NMB-R-deficient mice. First, the quantity of the cDNA template was adjusted by amplifying the $\beta$-actin gene. Then, using the same amount of cDNA template for wild-type and NMB-R-deficient mice, genes for three BN-like peptide receptors were amplified. As shown in Figure $2 B$, the expression of the normal NMB-R gene was abolished in NMBR-deficient mice, but the expression levels of the other two genes, GRP-R and BRS-3, were not changed compared with the wildtype mice.

\section{Smooth muscle contraction in NMB-R-deficient mice}

One of the major physiological activities of $\mathrm{BN}$ is the regulation of smooth muscle contraction (Lebacq-Verheyden et al., 1990). To elucidate the role of NMB-R in this activity, we examined the contractile responses of the fundus in the NMB-R-deficient mice. Peak contraction induced by $60 \mathrm{mM} \mathrm{KCl}$ was not affected in NMB-R-deficient mice. NMB elicited the contraction of the fundic muscle in a dose-dependent manner, and this response was similar in both wild-type and NMB-R-deficient mice (Fig. 4A). The $\mathrm{ED}_{50}$ values, determined from dose-response curves of individual mice, were $14.4 \pm 2.3 \mathrm{~nm}(n=8)$ and $10.9 \pm 2.3 \mathrm{~nm}(n=$ 8) for wild-type and NMB-R-deficient mice, respectively. Additionally, the concentration-dependent responses to GRP also were unchanged in NMB-R-deficient mice (Fig. $4 B$ ). The ED $_{50}$ 
A

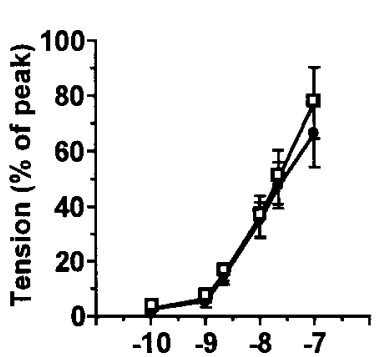

NMB concentration $(\log M)$

B

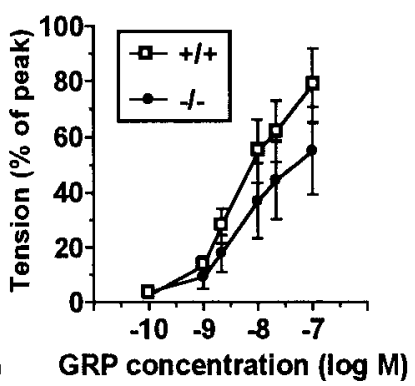

Figure 4. Smooth muscle contraction in the gastric fundus. Concentration-response curves for NMB $(A)$ or GRP $(B)$ show that the contractile responses to both NMB and GRP were not affected in NMB-R-deficient mice. Data are expressed as percentage of peak tension induced by $60 \mathrm{~mm}$ $\mathrm{KCl}$. Values are mean \pm SEM.

values were $7.1 \pm 1.3 \mathrm{~nm}(n=6)$ for wild-type and $8.3 \pm 2.2 \mathrm{nM}$ $(n=6)$ for mutant mice. Our data suggest that NMB and GRP are both potent stimulators for fundic smooth muscle contraction, and the response of the fundus to these peptides was similar in NMB-R-deficient and wild-type mice.

\section{Expression of $\mathrm{BN}$-like peptide receptors in the fundus}

Of the three BN-like peptide receptors, only BRS-3 is not expressed in gastric tissue (Ohki-Hamazaki et al., 1997a). Therefore, we only examined the expression levels of NMB-R and GRP-R in the fundus. First, the amplification efficiencies of two sets of primers for each receptor were compared. As shown in Figure $5 A$, when the same amount of cDNA was used as a template, both pairs of primers yielded almost the same amount of PCR products. This means that the amplification efficiencies of these primers are comparable. Using an equal amount of fundus cDNA from wild-type mice, the PCR product for the GRP-R gene already was detected at 30 cycles, but the amplified product for NMB-R was detected only after 34 cycles (Fig. 5B). This indicates that the expression of the GRP-R gene predominates in the fundus. We also compared the expression level of GRP-R in the fundus of wild-type and NMB-R-deficient mice. The amount of the template was adjusted by amplifying the $\beta$-actin gene, and then the GRP-R gene was amplified by using the same amount of template for the two genotypes. It was revealed that the expression level of GRP-R was not changed in NMB-R-deficient mice (Fig. 5B).

\section{Feeding suppression induced by $\mathrm{BN}$-like peptides was not affected in NMB-R-deficient mice}

Satiety is one of the most potent functions of BN and BN-like peptides revealed so far (Lebacq-Verheyden et al., 1990). To elucidate the contribution of NMB-R and GRP-R and their ligands in mediating this function, we evaluated the effect of peripheral administration of NMB or GRP (Fig. 6). We could not detect the effect of NMB administration on feeding suppression even in wild-type mice. In contrast, GRP could elicit a satiety effect in both wild-type and NMB-R-deficient mice. The potency of GRP was not different in the two genotypes. Therefore, feeding suppression by GRP was maintained in NMB-R-deficient mice.

\section{Comparison of behavior between NMB-R-deficient and} GRP-R-deficient mice

The phenotype of GRP-R-deficient mice was characterized by an increased locomotor activity and pronounced social responses
A

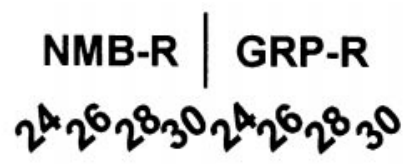

M13 primers

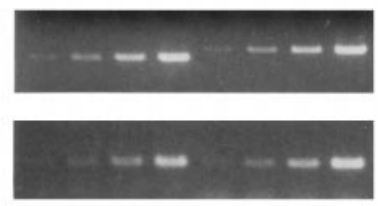

BN primers

B
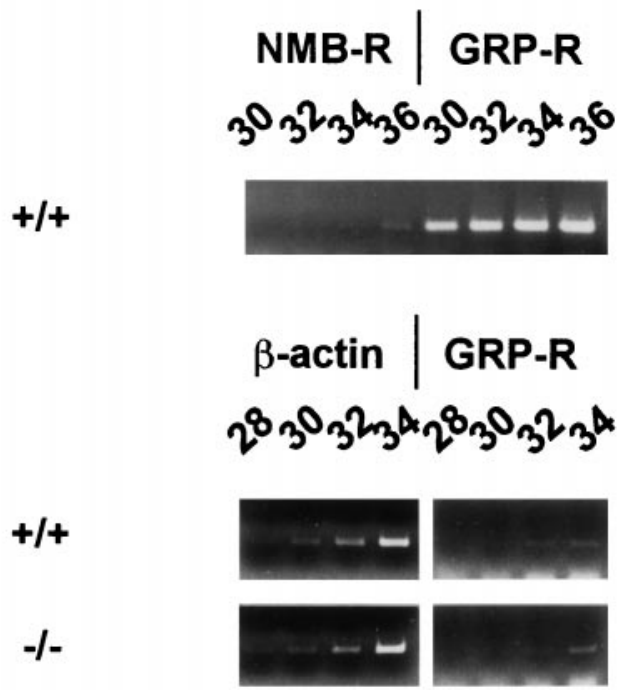

Figure 5. NMB-R and GRP-R gene expressions in gastric fundus. $A$, Comparison of amplification efficiencies of NMB-R and GRP-R primers. Plasmids containing mouse NMB-R or GRP-R cDNA were used as templates (indicated at the top of the panels). Concentration of templates was adjusted using PCR with M13 forward and reverse primers. Products were analyzed at the indicated cycles. The bottom panel shows the results of PCR with NMB-R primers (for NMB-R cDNA template) and GRP-R primers (for GRP-R cDNA template), indicating that the PCR efficiencies were comparable for NMB-R and GRP-R primers. $B$, Expression of NMB-R and GRP-R in the gastric fundus. In wild-type mice, GRP-R expression is predominant compared with the NMB-R. Using the same amount of cDNA from wild-type and NMB-R-deficient mice (determined by PCR with $\beta$-actin primers), PCR with GRP-R primers reveals that the expression of the GRP-R gene is not upregulated in NMB-Rdeficient mice.

(Wada et al., 1997). To determine whether the same phenotype is present in NMB-R-deficient mice, we performed the same behavioral analysis. Locomotor activity, monitored under a $12 \mathrm{hr}$ light/dark cycle, was not affected in NMB-R-deficient mice (Fig. $7 A$ ). We also examined activity in a novel environment, but the 60 min activity of the NMB-R-deficient mice was comparable to that of the wild-type mice (Fig. $7 B$ ). Finally, we did not observe any differences in nonaggressive or aggressive social behaviors in mutant mice compared with the wild-type mice (Fig. $7 C, D$ ).

\section{DISCUSSION}

Generation and analysis of gene-targeted mice is a useful tool for the investigation of the individual gene function. For molecules involved in a family or subfamily, this technique is obviously more potent than the pharmacological one, because the lack of specific antagonists often makes it difficult to distinguish the functions of structurally similar molecules in the same family. Even when the antagonists are available, the long-term application of the antag- 


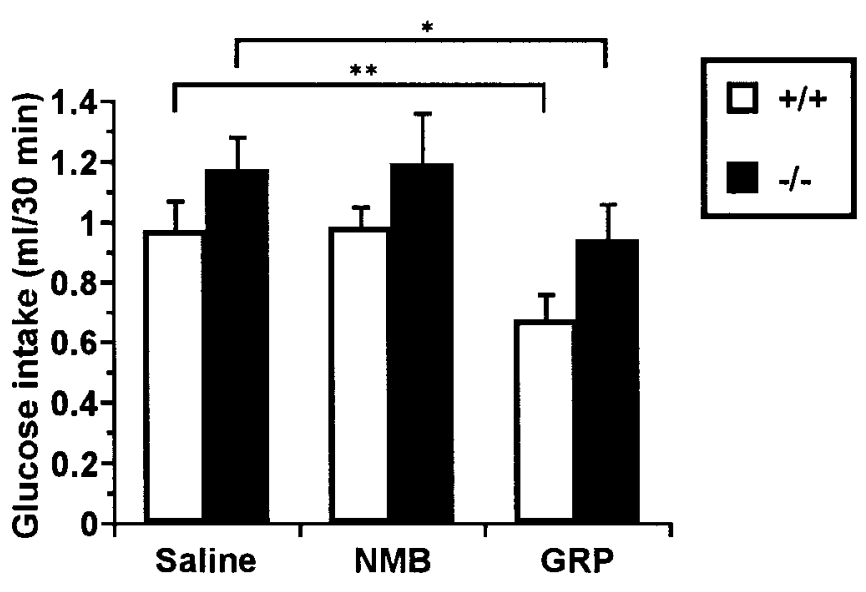

Figure 6. Effect of NMB or GRP administration on glucose intake. Intake of glucose solution after intraperitoneal injection of saline, NMB, or GRP was measured. GRP induced a significant suppression of glucose intake in both NMB-R-deficient and wild-type-mice, but NMB failed to produce this effect in both mice. Values are mean \pm SEM. ${ }^{*} p<0.05$; ${ }^{* *} p<0.01$.
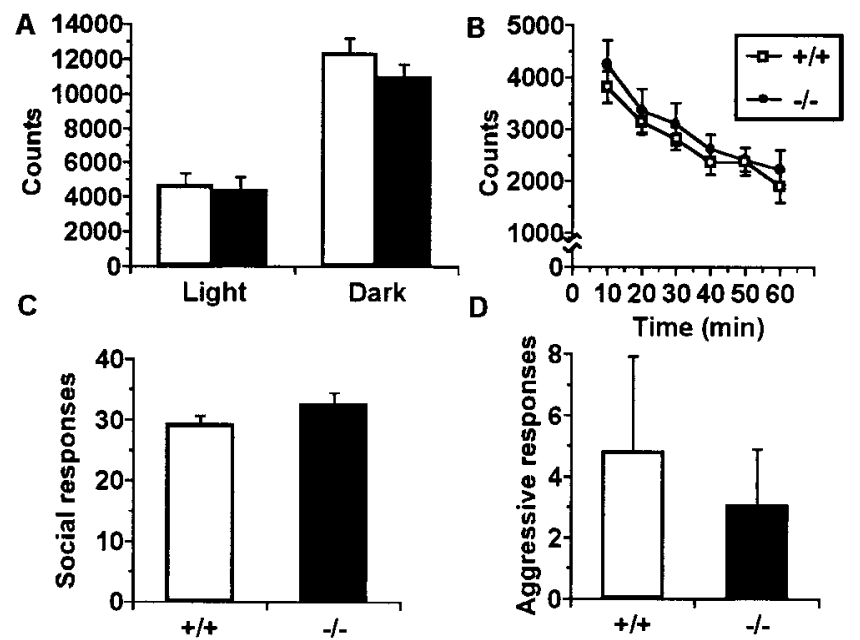

Figure 7. Behavioral measurements of NMB-R-deficient mice. Longterm $(24 \mathrm{hr})$ activity measured in their home cage $(A)$ and short-term activity (every $10 \mathrm{~min}$ for $60 \mathrm{~min}$ ) under novel environment $(B)$ were not affected in NMB-R-deficient mice. Social interaction was evaluated by counting the scores of nonaggressive (sniffing, following, mounting, and approaching the intruder) $(C)$ and overt aggressive social behaviors (biting, fighting, and vocalization against the intruder) $(D)$. Social interaction of NMB-R-deficient mice was comparable to the wild-type mice. Values are mean \pm SEM.

onists to the whole-animal level is almost impossible. The BN-like peptide receptor subfamily consists of three receptors: NMB-R, GRP-R, and BRS-3. Previously, we generated and characterized the GRP-R- and BRS-3-deficient mice (Ohki-Hamazaki et al., 1997b; Wada et al., 1997). Generation of the NMB-R-deficient mice reported in this paper enables us to compare the functions of these three receptors.

Here we show that mice with a targeted mutation in the NMB-R gene failed to produce functional NMB-R. Maintenance of body temperature after a change in ambient temperature, contraction of the gastric smooth muscle elicited by NMB or GRP, and feeding suppression by GRP were not affected by elimination of NMB-R. In contrast, the hypothermic effect of NMB was reduced by $50 \%$ in the NMB-R-deficient mice. Be-
Table 1. Summary of BN-like peptides and receptors functions in mice

\begin{tabular}{|c|c|c|c|c|}
\hline & \multicolumn{2}{|c|}{ NMB-R } & \multicolumn{2}{|c|}{ GRP-R } \\
\hline & NMB & GRP & NMB & GRP \\
\hline Thermoregulation & + & - & + & + \\
\hline $\begin{array}{l}\text { Smooth muscle contraction } \\
\text { (fundus) }\end{array}$ & - & - & + & + \\
\hline Food intake & - & - & - & + \\
\hline
\end{tabular}

cause the locomotor activity and social behavior were not disturbed in these mice, it is concluded that the functions of GRP-R and NMB-R are distinct (Table 1).

It is evident that the NMB-R has a thermoregulatory role (Fig. 3 , Table 1). In the absence of NMB-R, the effect of NMB infusion on hypothermia was reduced by $50 \%$ (Fig. 3B). This effect may be mediated by the action of NMB on GRP-R, which has a low affinity for NMB. The upregulation of GRP-R expression in whole brain did not occur in NMB-R-deficient mice (Fig. $2 B$ ), indicating that the compensatory response by GRP-R remains only partial. However, NMB-R-deficient mice have normal thermoregulatory responses when exposed to cold. Our data showed that the response to GRP in NMB-R-deficient mice is comparable to wild-type mice, and the hypothermic effect of GRP seems to be more potent than NMB (Fig. 3B). Moreover, considering other neuropeptides that can act as regulators of body temperature, it is conceivable that NMB-R-deficient mice have normal thermoregulatory responses when challenged by cold exposure (Fig. $3 A$ ). This implies that the thermoregulatory role of NMB-R is conditional and may be important for the precise regulation of body temperature. Although the difference in sensitivity to NMB is clear by our results, it will be important to evaluate a dose effect of the peptides on body temperature for further understanding.

In contrast, we could not demonstrate the role of NMB-R in smooth muscle contraction of the fundus (Fig. 4, Table 1). Our data showed that NMB-R was not essential for the contractility of fundic muscle, indicating that the activity of GRP-R compensates for that of NMB-R. This fact is supported further by RT-PCR, which shows that the expression of GRP-R is predominant in the gastric fundus (Fig. 5B). In the rat, receptor autoradiography and contraction studies suggested that in the gastric fundus, the GRP-R is the main receptor subtype mediating the contraction by BN (Ladenheim et al., 1997). Contraction assays using GRP-Rdeficient mice will provide the precise contribution of NMB-R, but with our data it can be concluded that the contraction of the murine fundus produced by $\mathrm{BN}$-like peptides is mediated by GRP/GRP-R and NMB/GRP-R interactions. Although it has been shown that both NMB-R and GRP-R are expressed in the stomach of rat embryos from 14 to $20 \mathrm{~d}$ postcoitus (Wada et al., 1993), the lack of NMB-R expression during the embryonic ages does not seem to influence the development of the stomach.

Feeding suppression by GRP was not affected in NMB-Rdeficient mice, suggesting that the satiety effect of BN-like peptides is solely mediated by GRP/GRP-R in mice (Fig. 6, Table 1). Evaluation of dose effect is needed for precise analysis, but our data are consistent with Hampton et al. (1998) who demonstrated that mice lacking GRP-R totally lost the satiety response to BN. However, studies using receptor antagonists suggested that the $\mathrm{NMB} / \mathrm{NMB}-\mathrm{R}$ has an effect, although less potent than $\mathrm{BN}$ or GRP, on feeding suppression in rat (Ladenheim et al., 1994, 
1996). This discrepancy may be attributed to the species difference, but it remains true that the GRP/GRP-R system is predominant for feeding suppression in both species.

Inactivation of GRP-R resulted in the elevation of the activity during the active period (dark period in light/dark cycles) and activation of social behavior (Wada et al., 1997). We performed the same analysis for NMB-R-deficient mice, but we could not find any difference between wild-type and NMB-R-deficient mice (Fig. 7). This shows that these phenotypes are unique consequences of the GRP-R deficiency. In addition, NMB-R-deficient mice are not obese, which is the main phenotype of BRS-3deficient mice (Ohki-Hamazaki et al., 1997b).

In summary, targeted disruption of the NMB-R demonstrated a role for NMB-R in thermoregulation, but not for smooth muscle contraction of the fundus or feeding suppression, which could be exhibited by the function of the GRP-R. Physiological and behavioral features of three lines of BN-like peptide receptor-deficient mice were distinct, suggesting that these three receptors, i.e., NMB-R, GRP-R, and BRS-3, have independent functions.

\section{REFERENCES}

Anastasi A, Erspamer V, Bucci M (1971) Isolation and structure of bombesin and alytesin, two analogous active peptides from the skin of the european amphibians Bombina and Alytes. Experientia 27:166-167.

Battey JF, Way JM, Corjay MH, Shapira H, Kusano K, Harkins R, Wu JM, Slattery T, Mann E, Feldman RI (1991) Molecular cloning of the bombesin/gastrin-releasing peptide receptor from Swiss 3T3 cells. Proc Natl Acad Sci USA 88:395-399.

Corjay MH, Dobrzanski DJ, Way JM, Viallet J, Shapira H, Worland P, Sausville EA, Battey JE (1991) Two distinct bombesin receptor subtypes are expressed and functional in human lung carcinoma cells. J Biol Chem 266:18771-18779.

Fathi Z, Corjay MH, Shapira H, Wada E, Benya R, Jensen R, Viallet J, Sausville EA, Battey JF (1993) A novel bombesin receptor subtype selectively expressed in testis and lung carcinoma cells. J Biol Chem 268:5979-5984.

Gorbulev V, Akhundova A, Buchner H, Fahrenholz F (1992) Molecular cloning of a new bombesin receptor subtype expressed in uterus during pregnancy. Eur J Biochem 208:405-410.

Hampton LL, Ladenheim EE, Akeson M, Way JM, Weber HC, Sutliff VE, Jensen RT, Wine LJ, Arnheiter H, Battey JF (1998) Loss of bombesin-induced feeding suppression in gastrin-releasing peptide receptor-deficient mice. Proc Natl Acad Sci USA 95:3188-3192.

Hooper M, Hardy K, Handyside A, Hunter S, Monk M (1987) HPRTdeficient (Lesch-Nyhan) mouse embryos derived from germline colonization by cultured cells. Nature 326:292-295.

Krane IM, Naylor SL, Helin-Davis D, Chin WW, Spindel ER (1988) Molecular cloning of cDNAs encoding the human bombesin-like peptide neuromedin B. J Biol Chem 263:13317-13323.

Kris RM, Hazan R, Villines J, Moody TW, Schlessinger J (1987) Identification of the bombesin receptor on murine and human cells by cross-linking experiments. J Biol Chem 262:11215-11220.

Ladenheim EE, Taylor JE, Coy DH, Moran TH (1994) Blockade of feeding inhibition by neuromedin B using a selective receptor antagonist. Eur J Pharmacol 271:R7-R9.

Ladenheim EE, Wirth KE, Moran TH (1996) Receptor subtype mediation of feeding suppression by bombesin-like peptides. Pharmacol Biochem Behav 54:705-711.
Ladenheim EE, Moore KA, Salorio CF, Mantey SA, Taylor JE, Coy DH, Jensen RT, Moran TH (1997) Characterization of bombesin binding sites in the rat stomach. Eur J Pharmacol 319:245-251.

Lebacq-Verheyden A-M, Krystal G, Sartor O, Way J, Battey JF (1988) The rat prepro gastrin releasing peptide gene is transcribed from two initiation sites in the brain. Mol Endocrinol 2:556-563.

Lebacq-Verheyden A-M, Trepel J, Sausville EA, Battey JF (1990) Bombesin and gastrin releasing peptide: neuropeptides, secretogogues, and growth factors. In: Handbook of experimental pharmacology, Vol 95/II. Peptide growth factors and their receptors II (Sporn MB, Roberts AB, eds), pp 71-124. Berlin: Springer.

Lin KS, Lin MT (1986) Effects of bombesin on thermoregulatory responses and hypothalamic neuronal activities in the rat. Am J Physiol 251:R303-309.

McDonald TJ, Jornvall H, Nilsson G, Vagne M, Ghatei M, Bloom SR, Mutt V (1979) Characterization of a gastrin releasing peptide from porcine non-antral gastric tissue. Biochem Biophys Res Commun 90:227-233.

Minamino N, Kangawa K, Matsuo H (1983) Neuromedin B: a novel bombesin-like peptide identified in porcine spinal cord. Biochem Biophys Res Commun 114:541-548.

Ohki-Hamazaki H, Wada E, Matsui K, Wada K (1997a) Cloning and expression of the neuromedin $\mathrm{B}$ receptor and the third subtype of bombesin receptor genes in the mouse. Brain Res 762:165-172.

Ohki-Hamazaki H, Watase K, Yamamoto K, Ogura H, Yamano M, Yamada K, Maeno H, Imaki J, Kikuyama S, Wada E, Wada K (1997b) Mice lacking bombesin receptor subtype-3 develop metabolic defects and obesity. Nature 390:165-169.

Pittman QJ, Tache Y, Brown MR (1980) Bombesin acts in preoptic area to produce hypothermia in rats. Life Sci 26:725-730.

Spindel ER, Chin WW, Price J, Rees LH, Besser GM, Habener JF (1984) Cloning and characterization of cDNAs encoding human gastrin-releasing peptide. Proc Natl Acad Sci USA 81:5699-5703.

Spindel ER, Giladi E, Brehm P, Goodman RH, Segerson TP (1990) Cloning and functional characterization of a complementary DNA encoding the murine fibroblast bombesin/gastrin releasing peptide receptor. Mol Endocrinol 4:1956-1963.

Wada E, Way J, Lebacq-Verheyden AM, Battey JF (1990) Neuromedin $\mathrm{B}$ and gastrin-releasing peptide mRNAs are differentially distributed in the rat nervous system. J Neurosci 10:2917-2930.

Wada E, Way J, Shapira H, Kusano K, Lebacq-Verheyden AM, Coy D, Jensen R, Battey J (1991) cDNA cloning, characterization, and brain region-specific expression of a neuromedin-B-preferring bombesin receptor. Neuron 6:421-430.

Wada E, Wray S, Key S, Battey J (1992) Comparison of gene expression for two distinct bombesin receptor subtypes in postnatal rat central nervous system. Mol Cell Neurosci 3:446-460.

Wada E, Battey J, Wray S (1993) Bombesin receptor gene expression in rat embryos: transient GRP-R gene expression in the posterior pituitary. Mol Cell Neurosci 4:13-24.

Wada E, Watase K, Yamada K, Ogura H, Yamano M, Inomata Y, Eguchi J, Yamamoto K, Sunday ME, Maeno H, Mikoshiba K, Ohki-Hamazaki H, Wada K (1997) Generation and characterization of mice lacking gastrin-releasing peptide receptor. Biochem Biophys Res Commun 239:28-33.

Wunder BA, Hawkins MF, Avery DD, Swan H (1980) The effects of bombesin injected into the anterior and posterior hypothalamus on body temperature and oxygen consumption. Neuropharmacology 19:1095-1097.

Yagi T, Nada S, Watanabe N, Tamemoto H, Kohmura N, Ikawa Y, Aizawa S (1993) A novel negative selection for homologous recombinants using diphtheria toxin A fragment gene. Analyt Biochem 214:77-86. 